\title{
The Designing Expressions of the Special Visual Effect Film in the Digital Technology
}

\author{
Tsun-Hsiung $\mathrm{Yao}^{1}$ and Chu-Yu $\mathrm{Sun}^{2}$ \\ ${ }^{1}$ Department of Visual Design, National Kaohsiung Normal University \\ ${ }^{2}$ Graduate School of Applied Design \& Department of Animation and Game Design, \\ Shu Te University of Science and Technology \\ yaotsunanknu.edu.tw
}

\section{Introduction}

From 1950 when computer technology began to undertake the creation of computer art, the creation of these "digital works" became a new tool and medium for artistic expression. This also had a major impact on visual artistic expression. This paper takes science fiction movies as the textual source of its research and analyzes the commercial messaging and artistic expression of thematic images within the cinematic arts. Science fiction movies have always emphasized the surreal and when they a place beyond our spatio-temporal realm into their form of artistic expression, it is necessary to overcome many technical difficulties before a realistic virtual scene can be built. As such, special effects movies can be said to operate using the newest products of media technology. Through researching various special effects in science fiction movies, we can understand the corresponding period's newest technologies, methods, and advances in movie production and more incisively understand "the entrance of the territory of artistic expression into the digital age."

\section{Types of Movie Special Effect Technologies}

Movie special effects can be broadly classified into four types: make-up, modeling, animation, and cinematography. The production process can be divided into the two stages. In the earlier stage properties are created such as models, make-up, and manmade sets. Later production includes computer animation and shooting the movie. Among these, shooting can be divided into special effects cinematography and the integrated optical technology of synthesized cinematography.

\subsection{Special Make-Up}

The greatest difference between modeling and make-up, is that make-up is applied to the actual performers so that they are able to perform the role of a character completely unlike their own. There are many materials which can be used in make-up, and its technical aspects must be able to change constantly in order to satisfy movie scripts. The technical consideration for make-up is that it must cause audience members to 
suspend their disbelief and thus must create fictional characters they can accept. Early examples of this technology is The Wizard of Ox (1939), The Exorcist (1973), and An American Werewolf in London (1981), which received an Oscar for best makeup, as well as The Planet of the Apes (1968) which used foam rubber, then a technological breakthrough. Planet of the Apes won a special Oscar to praise its contribution to film history for its makeup, and is part of the permanent collection of the United States National Film Preservation Board.

\subsection{Miniature}

The early movies used miniature models based on economic considerations. Nowadays movies are willing to use large amounts of capital and see realistic model effect as a necessity. The goal of these models is to provide more stimulation and room for inspiration to modern people an abundant experience of digital visual effects. The value of models lies in "creating reality" and it is not demanded the audience believe the models are real. In early cinema models were often miniatures used for filming, and there were also extremely large models made especially for close-ups. An example of this is the filming King Kong (1933), which in addition to an overall body miniature of King Kong, also utilized an extremely large model of one of King Kong's arms in which the female lead was held. The ILM Company created a whale miniature for the movie Star Trek 4: The Voyage Home (1986).

\subsection{Animation}

Animation can be classified into two-dimensional, three dimensional, claymation, real people and computer synthesized animation. At present the creation process for animation is already a digital endeavor and is done through "Computer Generated Imagery." In analog movies with explosion scenes, or virtual actions of nature are all places where the work of CGI can be seen. Disney and Pixar are the two animated film producers primarily involved in CGI technology. With its first time synthesis of actual people and animation which lasted 10 minutes in 1964, the classic Marry Poppins was noteworthy in the history of cinema. In 1982, Tron became the first film to use large scale computer generated animation in shooting. In 1995, Toy Story became the first three-dimensional animated movie.

\subsection{Composite Photography}

The steps in undertaking post production for cinematography can be divided into the first period and the later period. The duties in first period is primarily include "the photography of miniature, in-camera techniques, the stop motion shooting involved in Claymation, projection, regular shooting, and new techniques like motion control. The later stage, by contrast, involves delves into optical printing, and matte, as well as other special effect treatment. Works which notably used lots of cinematic techniques include The Invisible Man, Star Wars, which in 1977 utilized motion control which included repeated reshooting principles; this movie also displayed 30 spaceships 
along with paintings of space. In 1978 Superman used "blue screen synthesis" and in Alien utilized introjections not long after in 1979. The 1992 film "Honey, I Blew Up the Kinds" utilized forced perspective photography, Tim Burton used stop motion for the Claymation work "Claymation Animation."

\subsection{Digital Special Effects in Films}

Digital movie effects can be divided into the three areas of compositing, computer graphics, animatronics. The term animatronics is a combination of the terms "animation" and "electronics." At present, many movies are dependent on computer aided technology for their completion, and this means producers are relying more and more on computer aided digital technology in order to achieve believable visual effects. Examples of this include the giant from the 2003 movie Big Fish. In fact the actor who played the giant was already over 2 meters tall. However, digital editing was still used in post production to change his appearance, thus making him stand out as unusually large. Computer art can also utilize electronic computing technologies which "create something out of nothing" with respect to visual effects. Examples of this include the hairy monster in Monsters, Inc (2001). This creature's moving fur was created by computer one hair at a time by the creation team. Another example is the Truman Show's (1999) photomontage graphic collage effect, which was the product of a computer program and, what is more, software such as Arc Soft Photo Montage was developed and marketed based on this technology. Events of nature are also created through the application of CGI technology, as seen in a natural scene from The Day After Tomorrow in which water submerges a city. The virtual fire and liquid metal, as well as ice and other elements created via computer technologies for the Fantastic Four (2005) is an example of the applications of computer technologies in cinema which are already too numerous to count.

\section{Application of Digital Technologies in Cinema}

The first critical point in movie special effects being permeated by digitalization was the use of motion repeater system technologies by Paramount Pictures. The main principle behind this technology was that movement of a camera's angle could be recorded and then precisely repeated, which made equivalent scale modeling filming more possible. Later this was developed into computer motion control, which created the production effect of allowing the computer to control movie animation and modeling, which represented an epic technological breakthrough and progress. Hereafter, digitalization for cinematic special effects soon became the standard and approached red hot during the 1990 digital age. In the series of "Digital Movie Special Effects" conferences the Autodesk Company held in 2006, Andrew Lesnie, in a talk he hosted entitled "Computer Art in the Digital Age" recalled "from the fifties to the sixties, this period in time, there were many different cinematic and optical production methods which were used in the movie industry. However, in the nineties these different systems slowly became the standard and stable part of the industry, and digital art, which 
was in its early stages during this period, started to exert an extremely large influence on the movie industry." Lesnie, is a director of photography, which is part of special effects, and won a Best Special Effects for Lord of the Rings (2001) in 2002, and a Best Visual Effects Award from the British Academy of Film and Television Arts, as well as the 2006 Best Visual Effects Oscar for King Kong (2005). Digitalization created a technical frame work for movies and influenced the mode of movie productions. For example, the relatively new digital postproduction system Digital Intermedia can turn traditional linear color grading into non-linear color grading, and the productivity of movie production is improved while through the adoption of digitalization. In recent years there is a trend toward digitalization system research and development being adopted in the movie production process. Many new technology developments are the result of overcoming problems during shooting. Examples of this include the Lustre Color Grading. Because climatic changes at the time of filming Lord of the Rings on location in New Zealand a color difference problem arose. The Lustre system has been used in many special effect movies since the Lord of the Rings.

\section{Movie Promotion under the Pursuit of Commercialism}

Movie Promotion involves the visually registered image given to audiences of movies being shown; in addition, it also accurately conveys the movie's theme. For this reason, the internal and external aspects which must be considered are many during design. Internal aspects include complicated content such as the spiritual theme, aspirational purpose, narrative structure, content variety, artistic creation, and other aspects. External aspects include: the artistic style of the director, the actors' screen images, properties, costumes, sets and scenery, as well as any particular items related to that film. These are all elements which must be considered in the visual design of a movie.

\subsection{Emphasis on Advantages of Movies}

Many special effects movies have become box office champions, and watching them is like being present at a rich visual feast. After watching them, audiences have the feeling of having directly experienced in a fantastic visual voyage, and this is the main reason the public loves special effects movies. In cinematic history, the two movies which 11 Oscars happened to be special effects movies. For example, the poster of the movie Ben Hur "Winner of 11 Academy Awards is printed in large letters, thus noting the prizes it has obtained. By contrast, the sentence "From the director of 'Aliens,' 'T2' and 'True Lies'" appears on the poster for Titanic, thus noting the assuredly quality movies the director has undertaken, and these statements appearing on the poster pursue a commercial selling point. Special effects movies are the accomplishment of many expert production departments brought together. For this reason, the aspects and steps involved in them are broader than other types of films. 
If a special effects movie is noted as the winner of many awards, its value added will increase and the public will gladly pay to see special effects movies as a result and consumers will feel they got a full return on the ticket price.

\subsection{Hollywood Poster's Dominating Visual Effects}

Movie posters hide a great deal of forced visual consumption, and this commercial methodology is reflected in Hollywood movies with major stars in the lead. These include the posters for War of the Worlds, Mission: Impossible. In the poster for these movies there is no mention of special effects; rather, all you can see is Tom Cruise's face, and the star's countenance becomes the only piece of information available on the poster. Burt Lancaster stated that: "The audience buys their tickets and goes into the movie theater precisely because they want to see Tom Cruise himself, and not the various characters he plays." In Hollywood's star system, there is a commercial formula in which a group of stars translate into box office success. Hollywood has most definitely classic screen characters in different generations, and these stars certainly have a great impact on the box office. Close-ups of these stars also are utilized for the advertising of movies they play command roles in.

\subsection{Multi-version Poster Specifications for Sequels}

Science fiction movies have made the sequel very prevalent and, in related promotional material, there is also a mode of operations which is accompanies this promotion. The period before a movie is released is a commercial golden period. Movie makers are becoming ever more generous and refined in both the quantity and quality of poster printing, as posters play an important role in advertising. Multiple versions of stills have become the method in of box office promotion for sequels in the present period. Examples of this include Transformers, which presents fine and exhilarating skills in its posters. These posters utilize computer generated effect, which have already become more advanced and well used, to add cold grey, bluish cold grey, reddish brown and other warm and cold tones. This displays tones of the same style, but with a diverse composition and visually tense effect. Pirates of the Caribbean posters utilize continuous graphic elements to present the film's theme and unique stills of every main character. In addition, there are two uniquely colored poster versions for each actor, as well as a version with all of the actors together, for visual promotional use in various large movie theaters.

\subsection{Letter Figure Emblem as Logo Type for Increasing Sale of Peripheral Commercial Items}

Letters can become graphic elements in special effects movie posters, thus providing a graphic notion. On one hand this method can make the audience immediately understand the movie's theme, and on the other hand this element primarily assists in promoting peripheral commercial items extending from the film. An example of this is the Star Wars installment Return of the Jedi, which spent thirty to forty million in its 
production, and Willow, two movies in which 10 to 20 percent of budget was necessarily spent on visual effects. In addition, the greater benefit of blockbuster films (film rental) lies in the sale peripheral commercial item (including models, toys, and apparel), which can often earn more than the box office itself. Games based on the movie and recreational facilities such as theme parks are also items which can increase the overall profit of a top selling move. It is common to see movies utilize two or more different movie posters, with each one utilizing its own graphic logo. In addition, the script versions all integrate into the graphics. These letters become like pictures and do not perform their original function as a linguistic tool to be read, but rather become an element assisting in the visual affect of the poster. These graphic logos also completely become the face of peripheral commercial items and achieve the movies second wave commercial profit effect.

\subsection{Print Promotion Material Visual System as Determined by Directing Style}

George Lucas' Star Wars Series, from the 1977 Star Wars Episode IV: A New Hope to the 1980 The Empire Strikes Back, the 1983 Return of the Jedi, the 1999 Star Wars Episode I: The Phantom Menace, the 2002 Star Wars Episode II: Attack of the Clones, and the 2005 Star Wars Episode III: Revenge of the Sith show little variation in the visual style of their scenes. This is as a result of the director's core notions throughout this science fiction series, and well as the exploration of the original driving force throughout. In addition to this, the poster promotion style also evolved into a plain and easy to understand visual vocabulary for the Star Wars series.

\section{Conclusion}

Presently, cinematic special effects are developing ever more in the direction of digitalization, and many technical processes are already considered from the mode of digital undertakings. At present the CGI sector, which is responsible for the production of visual effects in movies and computer games, is a production structure formed as a result of technological advancements. Computer technology has also transformed production modes in the area of design. As a result, movie posters have seen a change from the early hand produced versions to the present two dimensional and three dimensional artistic works. Changes in publication media have also led naturally to variation in modes and methodologies for product promotion. With respect to "science fiction movie visuals," reasons influencing the fact that the greatest changes appeared between the present and the early period forms of promotional media can be traced two major items:

\subsection{Influence of Information Effects}

The twentieth century was the information age, and the advent of the internet changed manner in which all people around the world received information. The electronic media plays the role of rapid information dissemination, and people find themselves 
in a visual age exploding with information, and digitalization makes it easier to obtain, store, and copy images. People can obtain images from digital cameras, the internet, and smartphones, as well as other media devices quickly, conveniently, and often. This means humanity is evermore stimulated by the number of images it experiences, and its visual experiences accumulate over time as a result. The public appears less likely to be satisfied with expressions of mediocre art as time goes on. The information age phenomenon is reflected in movie posters, which resides within the scope of public culture, and this has meant more versions of these posters are produced. On one hand digitalization has made the production of graphic works faster and more economical than traditional hand drawn illustration. On the other hand, science fiction posters particularly emphasize visual effects. In order to avoid the effects involved with perceptual stimulation which is only temporary, movie makers utilize various different visual compositions in describing the same movie theme in creating promotional posters. The goal is to provide the audience with a rich and diverse visually enjoying experience.

\subsection{Influence of Commercial Effect}

Science fiction movies emphasize visuals, and "special effects" is necessarily a selling point for movies. It follows that, in terms of their surface, the posters for science fiction movies must move toward making the successful conveyance of "visual effects" a main consideration in their composition, and a concern of their design. Science fiction movies have, for a long time, been at the top of box offices. One impact of this fact is that posters for special effects movies must particularly pay close attention to "visual focal points" (key art) in the scenes they depict. These visual focal points also possess commercial selling points. This is the result of the influence which design considerations becoming commercialized and strategic. What is more, in the present information age a movie needs to develop a multimedia market in order to guarantee it will make large profits. Examples of this market include DVD rentals, pay per-view, and peripheral commercial products. This also provides design work with the opportunity to promote a movies from a wide variety of traditional and electronic media including posters, CD covers, DVD covers, script covers, pictures on busses, DM, newspapers, official websites, smartphones, and other items which cross various media platforms, which differ from the traditional hand drawn poster era.

\section{References}

1. Li, D.: Hollywood, Movies, and the Dream Factory. Yang Chih Publishers, Taipei (2000)

2. Wei, D.: Science Fiction Cinema: From Outerspace to Cyberspace by Geoff King and Tanya Krywinska. Shulin Publishing, Taipei (2003)

3. World Screen (August 1995)

4. Ye, J.: Intruduction to Digital Art. Artist Publishing, Taipei (2005)

5. Lester, P.M.: Visual Broadcast. Yeh Yeh Book Gallery, Taipei (2003)

6. Hershenson, B.: 100 years of the Cinema. Christie's East, New York (2000) 
7. Hershenson, B.: 100 years of the Cinema. Christie's East, New York (2000)

8. Hershenson, B.: Academy Award Winners' Movie Posters (2001)

9. Hershenson, B.: Vintage Hollywood Posters I, California (1999)

10. Hershenson, B.: Warner Bros. Movie Posters at Auction (2004)

11. King, E.: A Century of Movie Posters from Silent to Art House, Barron's (2003)

12. Barton, M.D.: Hollywood Movie Posters 1914-1990. Schiffer Publishing (2003)

13. Osborne, R.: "75 Years of the Oscar", Abbeville Press.Tony Nourmand and Graham Marsh, 2003"Film Posters of the 30s the essential movies of the decade. The Overlook, New York (2003) 